\title{
A Critical Comparison of Supplier Selection Methodologies
}

\author{
G. Bruno ${ }^{1}$, F. Ciardiello ${ }^{2}$, E. Esposito ${ }^{1}$, A. Genovese ${ }^{2}$, C.Piccolo $^{1}$ \\ ${ }^{1}$ Department of Industrial Engineering, University of Naples "Federico II", Italy \\ ${ }^{2}$ Logistics and Supply Chain Management Research Centre, University of Sheffield, UK
}

Keywords: Supplier Selection, Multi-Criteria Decision Making

Topics: Supply Chain and Networks, Supplier Selection

In an extremely competitive market context, consumers demand cheaper and higher quality products, on-time delivery and excellent after-sale services. Therefore, companies are under intense pressure to cut costs while maintaining a high level of quality and after-sale services. Various studies devoted to the analysis of customer-supplier relationships highlighted that, in order to improve the quality of the services and/or of the products provided to the final consumers, careful attention should be paid on the organization and management of the entire supply chain. Moreover, with the trend to outsource a constantly increasing quota of the value-chain activities, purchasing decisions become crucial. For these reasons a key role is played by the supplier evaluation process in order to set up a supply system able to rapidly react to market requirements and innovation process (Gules and Burgess, 1996; Sarkara and Mohapatrab, 2006; Saen, 2007). In particular, suppliers' selection has assumed a strategic role in determining large customer firms' competitiveness. Consequently, customers devote more and more resources both to suppliers' development programs and to early suppliers' involvement (O’Neal, 2006).

In this perspective supplier selection has received extensive attention in the literature (de Boer et al., 2001; Kamann and Bakker, 2004). Most of all, an increasing number of researches has been devoted to the development of different methodologies to cope with this problem (Bruno et al., 2012). Nevertheless, while the number of applications is growing at a steady rate (as shown in Figure 1, showing the number of papers being published yearly ${ }^{1}$ ), there is little empirical evidence of the practical usefulness of such tools (Bruno et al., 2012).

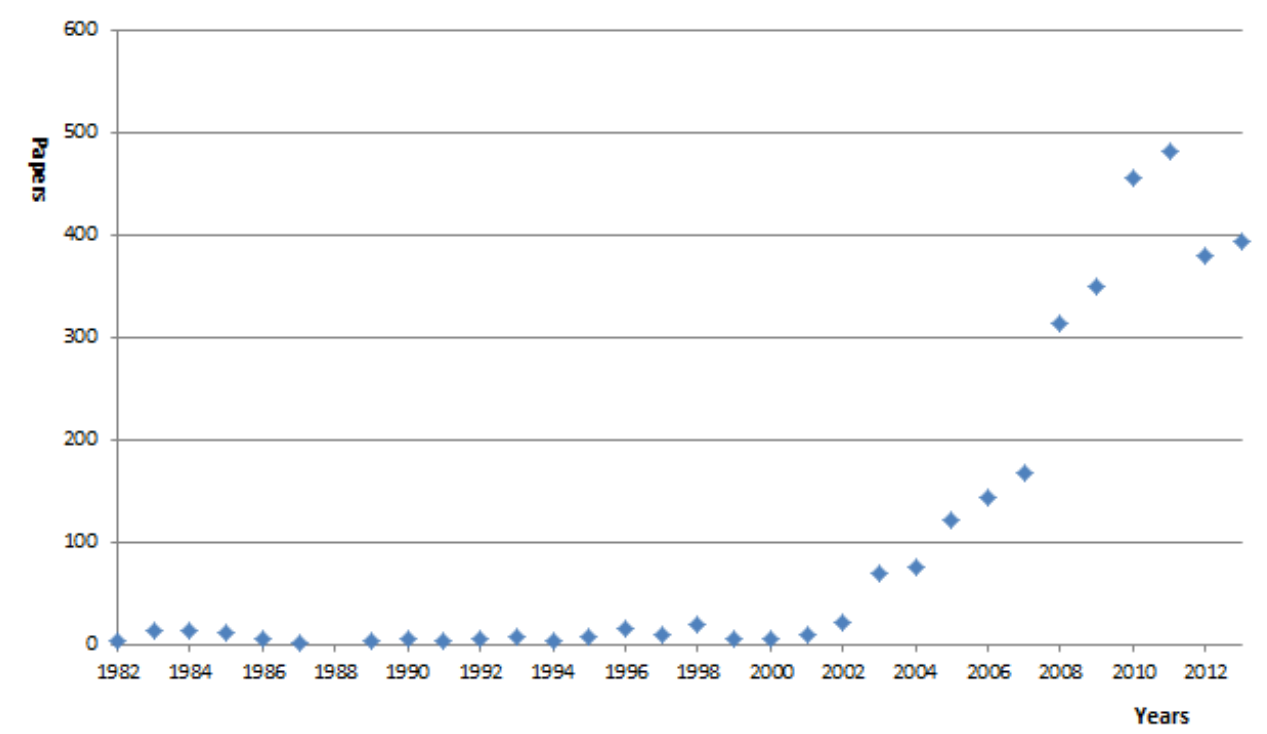

Figure 1: Historical Series of published papers dealing with the Supplier Selection Problem (Authors' own elaboration)

\footnotetext{
${ }^{1}$ The historical series reported in Figure 1 has been obtained by sourcing the papers from the academic search engine Scopus ${ }^{\mathrm{TM}}$ by employing the following syntax: ["Supplier Selection" OR "Vendor Selection" OR "Supplier Evaluation" OR "Vendor Evaluation" OR "Supplier Assessment" OR "Vendor Assessment"]. Contribution published on international journals have been reported.
} 
Moreover, the analysis of the literature shows that authors tend to stress the strengths of their models neglecting or giving little attention to the weaknesses. It is not by chance that, in many cases, proposed models are tested on generic applications, mainly including ad-hoc built numerical examples (Saen, 2007; Rodriguez et al., 2013), with less emphasis on issues and problems emerging in the actual implementation in real-world scenarios.

Furthermore, most of the approaches available in the literature fail to capture the inherent complexities deriving from the multi-stakeholder nature of the problem. Indeed, models and method often just focus on a dyadic version of the problem, overlooking the wider set of actors involved in the decision making problem (such as managers from different departments at the customer firm, second tier suppliers, end-users and their respective requirements).

The result is a clear dichotomy between theory and business practice (Bruno et al., 2012). In other words, the literature is rich of models which present a variety of approaches that are rarely used to solve real problems in the corporate practice (Genovese et al., 2013a; Genovese et al., 2013b); also, it is not clear what are the advantages and the disadvantages of specific techniques when compared to other ones, in terms of performances related to both computational results and decision support. The result is a strikingly growing body of literature, whose contribution, apart from technical aspects (related to the development of new methodologies), may be questionable. leaving both practitioners and scholars with doubts about the most appropriate technique to be used to solve the Supplier Selection Problem.

Considering this evidence, the goal of this paper is to contribute to understand and overcome the above dichotomy by evaluating the applicability to real-world problems of the two main approaches proposed in the literature to deal with the SS, the Analytic Hierarchic Process (AHP) and the Fuzzy Set Theory (FST).

After a thorough review of the literature, starting from the characteristics of AHP and FST approaches, and from their combination in a hybrid framework, we compare the performance of these three methodologies for dealing with the Supplier Selection Problem on the basis of:

- A set of randomly generated numerical examples, in order to gain insights about differences and similarities, from a computational point of view, emerging both in the implementation process and in the final recommendations provided by the methods. In particular, supplier rankings will be produced by employing each of the methodologies; concordances and discrepancies of the resulting rankings obtained by using the different methodologies will be evaluated according to appropriate statistical measurements and tests;

- an in-depth case study, in order to fully investigate the usability of the approaches and some managerial implications deriving from the implementation of the methodologies in a real-world corporate environment.

The paper will be organized as follows. Firstly, a thorough literature review will be proposed. It describes the main methods available in the literature for dealing with the SS problem, with a special focus on AHP and FST approaches. After that, the empirical studies are presented, starting from the randomly generated instances; then, the in-depth case study is analysed, along with a discussion about managerial implications is then developed. Finally, conclusions and future research perspectives are reported. 


\section{References}

de Boer L., Labro E., Morlacchi P. (2001). A review of methods supporting supplier selection, European Journal of Purchasing \& Supply Management, vol.7, pp.75-89.

Genovese, A., Lenny Koh, S. C., Bruno, G., Esposito, E. (2013a). Greener supplier selection: state of the art and some empirical evidence. International Journal of Production Research, 51(10), 2868-2886.

Genovese, A., Koh, S. C.L., Kumar, N., \& Tripathi, P. K. (2013b). Exploring the challenges in implementing supplier environmental performance measurement models: a case study. Production Planning \& Control, (ahead-of-print), 1-14.

Gules H.K., Burges T.F. (1996). Manufacturing technology and the supply chain. European Journal of Purchasing \& Supply Management, vol.2, n.1, pp.31-38.

Kamann D.F., Bakker E.F. (2004). Changing supplier selection and relationship practices: a contagion process. Journal of Purchasing \& Supply Management, vol.10, pp.55-64.

O'Neal C. (2006). Concurrent engineering with early supplier involvement: a cross functional challenge. Journal of Supply Chain Management, vol. 29, n.2, pp.2-9.

Saen R.F. (2007). A new mathematical approach for suppliers selection: Accounting for nonhomogeneity is important. Applied Mathematics and Computation, vol.185, pp. 84-95.

Rodriguez, A., Ortega, F. Concepcion, R. (2013). A method for the selection of customized equipment suppliers. Expert Systems with Applications, 40(4), 1170-1176.

Sarkara A., Mohapatrab P.K.J. (2006). Evaluation of supplier capability and performance: A method for supply base reduction. Journal of Purchasing \& Supply Management, vol.12, pp.148-163. 